\title{
ANGKA KAPANG DAN KHAMIR PADA LADA PUTIH ASAL BANGKA
}

\author{
Oktavio Rosani $^{1)}$, Devy Susanty ${ }^{1{ }^{*}}$, Ary Triyanto $^{2)}$ \\ ${ }^{1)}$ Program Studi Kimia FMIPA Universitas Nusa Bangsa Bogor \\ Jl. K.H. Soleh Iskandar Km. 4, Tanah Sareal, Bogor 16166 \\ ${ }^{2)}$ PT. Quindofood, Jl. Babakan Madang no 99 kompleks Darmawan Park gedung E, Bogor. \\ "e-mail: dvsusanty@gmail.com
}

\begin{abstract}
Numbers of Mold and Yeast on White Pepper from Bangka

White pepper is one of Indonesia's spices that are needed for both public consumption and exports. Postharvest processing of white pepper by farmers is often done with unclean. Each source of white pepper has different water content and will affect the quality of white pepper. In this study, seven samples (S1, S2, S3, S4, S5, S6, S7) were from Bangka. All samples tested had higher water content than SNI quality standard (13\%), but still below the quality standard 2 (18\%). Sample S2 has the highest water content compared to other samples. Sample S1 and S2 have high Numbers of Mold and Yeast (AKK) and do not suitable with quality standart of BPOM. Of all samples, S2 had the highest AKK (5,51 x 104 colony / g) and sample S5 had the smallest AKK (8,8 x 102 colony/g). This shows the relationship between water content in white pepper with AKK. White pepper that has a high water content has a high AKK, whereas white pepper that has low moisture content has low AKK.
\end{abstract}

Keywords: white pepper, Numbers of Mold and Yeast, moisture content

\begin{abstract}
ABSTRAK
Lada putih adalah salah satu rempah Indonesia yang banyak dibutuhkan baik untuk konsumsi masyarakat ataupun ekspor. Proses pengolahan pasca panen lada putih oleh petani sering dilakukan dengan tidak bersih. Setiap sumber lada putih memiliki kadar air yang berbeda dan akan mempengaruhi kualitas lada putih. Pada penelitian ini,tujuh sampel (S1, S2, S3, S4, S5, S6, S7) berasal dari Bangka. Semua sampel yang di uji memiliki kadar air yang lebih tinggi dari standar mutu 1 SNI (13\%), namun masih berada di bawah standar mutu 2 (18\%). Sampel S2 memiliki kadar air yang paling tinggi dibandingkan dengan sampel lainnya. Sampel S1 dan S2 memiliki (Angka Kapang Khamir) AKK yang tinggi dan tidak memenuhi syarat mutu. BPOM. Dari semua sampel, sampel S2 memiliki AKK paling tinggi $\left(5,51 \times 10^{4} \mathrm{koloni} / \mathrm{g}\right)$ dan sampel S5 memiliki AKK paling kecil $\left(8,8 \times 10^{2} \mathrm{koloni} / \mathrm{g}\right)$. Hal ini menunjukan hubungan antara kadar air pada lada putih dengan AKK. Lada putih yang memiliki kadar air tinggi memiliki AKK yang juga tinggi, sedangkan lada putih yang memiliki kadar air rendah memiki AKK yang rendah.
\end{abstract}

Kata Kunci: Lada putih, Angka kapang khamir, Kadar Air

\section{PENDAHULUAN}

Lada putih adalah salah satu rempah Indonesia yang banyak dibutuhkan baik untuk konsumsi masyarakat ataupun ekspor. Lada putih digunakan sebagai rempah pada berbagai jenis makanan bisa dengan cara dicampur saat proses memasak atau ditabur di atas makanan yang sudah matang. Oleh karena itu, lada putih yang beredar di pasar seharusnya dalam kondisi bersih sehingga tidak mengandung cemaran mikroba yang berbahaya bagi kesehatan masyarakat yang mengkonsumsinya.
Proses pengolahan pasca panen lada putih oleh petani sering dilakukan dengan tidak bersih. Beberapa tahapan proses pasca panen yang dilakukan tidak bersih diantaranya perendaman yang menggunakan air sungai atau air rawa, penjemuran dilakukan di tempat terbuka dan sortasi masih menggunakan tampir.

Untuk menghindari kerugian, para petani mengeringkan lada putih tidak sampai benar-benar kering atau masih dalam keadaan lembab. Kondisi lada putih yang tidak kering sempurna dikhawatirkan dapat meningkatkan jumlah jamur terutama kapang dan khamir, karena kapang dan 
khamir akan mudah tumbuh di bahan pangan yang lembab.

Berdasarkan penelitian yang dilakukan oleh Usmiati dan Nurjanah (2006), lada putih di daerah Kutai Kertanegara memiliki kadar air antara 10,4 $\%$ sampai $12,3 \%$ dengan nilai angka kapang berkisar antara $10^{2}$ koloni/g sampai $10^{4} \mathrm{koloni} / \mathrm{g}$. Setiap sumber lada putih memiliki kadar air yang berbeda. Oleh karena itu, perlu dilakukan penelitian lebih lanjut untuk melihat pengaruh kadar air terhadap nilai angka kapang dan khamir pada lada putih yang diperoleh dari petani di Bangka.

\section{BAHAN DAN METODE}

\section{Bahan dan Alat}

Bahan utama yang digunakan dalam penelitian ini adalah lada putih jenis Bangka berasal dari Pulau Bangka. Bahan lainnya adalah Maximum Recovery Deluent merk Scharlau, Potato Dextrose Agar merk Merk dan aquades. Peralatan yang digunakan yaitu neraca analitik ohauss 210 gram, cawan porselen $30 \mathrm{~mL}$, desikator, oven merk Memmert, oven merk BinderED 53, inkubator merk Binder BD-53, laminar air flow, botol semprot, blender, autoklave, pemanas berpengaduk, mikro pipet dan peralatan gelas lainnya.

\section{Metode}

\section{Pengumpulan Sampel}

Persiapan analisis sampel dilakukan dengan cara mengumpulkan lada putih dari Bangka sebanyak 7 sampel ( S1, S2, S3, S4, S5, S6, S7)

\section{Preparasi sampel}

Sampel lada putih yang sudah diberi kode dibersihkan terlebih dahulu, ditimbang bobot lada putih pada setiap masing-masing sampel dengan menimbang minimal 50 gram persampel. Penimbangan bobot lada putih dilakukan untuk menghindari adanya kekurangan sampel analisis. Sampel dihaluskan dengan blender. Sampel halus diambil sebagian untuk analisis kapang dan khamir, sampel yang tersisa digunakan untuk analisis kadar air.

\section{Penetapan Kadar Air (SNI 01-2891- 1992)}

Penetapan kadar air dilakukan dengan menimbang sampel halus sebanyak 1 gram, kemudian dimasukkan ke dalam cawan porselen yang sebelumnya telah dikeringkan dan diketahui bobot kosongnya. Sampel dikeringkan selama 3 jam pada suhu $105^{\circ} \mathrm{C}$, dimasukkan ke dalam desikator, dan setelah dingin ditimbang sampai mencapai bobot konstan. Persentase kadar air di dalam lada putih dihitung dengan rumus:

$$
\% \text { Kadar Air }=\frac{\mathrm{W} 1}{\mathrm{~W}} \times 100 \%
$$

Keterangan:

$\mathrm{W} 1=$ Bobot setelah dikeringkan

$\mathrm{W}$ = Bobot sebelum dikeringkan

\section{Penetapan Kapang dan khamir (SNI 01-2897-1992)}

Analisis kapang dan khamir membutuhkan beberapa tahapan yang harus dilakukan sebagai berikut:

\section{a. Sterilisasi Kering Alat}

Alat gelas yang akan digunakan untuk analisis kapang dan khamir dibungkus dengan aluminium foil, dan dikeringkan dalam oven selama 1 jam pada suhu $180^{\circ} \mathrm{C}$.

\section{b. Pembuatan Larutan Pengencer Maxmimum Recovery Deluent (MRD)}

Pembuatan larutan pengencer dilakukan dengan menimbang MRD sebanyak 4,5 gram lalu dilarutkan dalam $500 \mathrm{~mL}$ aquades dan diaduk di atas pemanas berpengaduk hingga homogen. Larutan MRD yang sudah homogen dituang sebanyak $45 \mathrm{~mL}$ ke dalam erlenmeyer dan dituang sebanyak $9 \mathrm{~mL}$ ke dalam tabung reaksi. Erlenmeyer dan tabung reaksi disumbat dengan kapas dan ditutup dengan aluminium foil, lalu disterilkan dengan 
autoklave selama 15 menit pada suhu $121^{\circ} \mathrm{C}$.

\section{c. Pembuatan Media Agar Potato Dextrose Agar (PDA)}

Pembuatan media agar dilakukan dengan cara menimbang PDA sebanyak 3,9 gram lalu dilarutkan dalam $100 \mathrm{~mL}$ aquades dan diaduk di atas pemanas berpengaduk hingga mendidih. PDA dituang ke dalam tabung reaksi sebanyak 12 . Tabung reaksi disumbat dengan kapas dan ditutup dengan aluminium foil, disterilkan dengan autoklave selama 15 menit pada suhu $121^{\circ} \mathrm{C}$.

\section{d. Analisis Kapang Khamir}

Lada putih yang sudah halus dan dipisahkan sesuai kode sampelnya ditimbang sebanyak 5 gram dan dituang ke larutan MRD $45 \mathrm{~mL}$, dikocok hingga homogen dan didiamkan hingga sampel mengendap. Larutan berisi sampel yang sudah mengendap dipipet sebanyak $1 \mathrm{~mL}$ dengan mikropipet, dituang ke dalam tabung reaksi pengenceran $10^{-1}$, sampai pengenceran $10^{-5}$. PDA yang suhunya sudah $45^{\circ} \mathrm{C}$ dituangkan ke dalam cawan petri sebanyak $12 \mathrm{~mL}$, dihomogenkan dan dibiarkan hingga media memadat. Cawan petri dimasukan dalam inkubator dengan suhu $25 \pm 2^{0} \mathrm{C}$ selama $5 \times 24$ jam. Untuk analisis sterilitas media dilakukan dengan menuangkan media PDA dalam cawan petri dan dibiarkan memadat sebagai kontrol.

\section{e. Perhitungan Angka Kapang dan Khamir (BPOM, 2006)}

Analisis uji kapang dan khamir dilakukan secara duplo pada setiap tingkat pengenceran. Penetapan angka kapang khamir dilakukan dengan cawan petri yang menunjukan jumlah antara 10-150 koloni. Cawan petri yang terbentuk 10-150 koloni dengan tingkat pengenceran yang sama, maka jumlah koloni per masing-masing cawan petri dihitung kemudian jumlah kedua koloni dikalikan dengan faktor pengencerannya. Jika pada cawan petri dari dua tingkat pengenceran yang berurutan menunjukan jumlah antara 10-150 koloni, maka dihitung jumlah koloni pada masingmasing cawan petri dan dikalikan faktor pengenceran, kemudian dari hasil perkalian tersebut diambil angka rata-rata. Hasil ratarata tersebut dibaca sebagai nilai angka kapang dan khamir dalam setiap gram atau mL sampel.

Angka kapang dan khamir = Rata- rata (koloni) $\times 10^{\mathrm{n}}$

Keterangan

$\mathrm{n}$ : Faktor pengenceran

\section{HASIL DAN PEMBAHASAN}

\section{Analisis Kadar Air}

Penentuan kadar air dilakukan dengan mengeringkan sampel dalam oven pada suhu $105^{\circ} \mathrm{C}$ selama 3 jam. Proses pengeringan dengan suhu di atas titik didih air menyebabkan proses hilangnya air dari sampel relatif cepat, sehingga waktu yang dibutuhkan untuk proses analisis lebih singkat. Jumlah air yang menguap adalah selisih bobot sampel sebelum dan sesudah pengeringan.

Analisis kadar air dilakukan untuk mengetahui kandungan air di dalam lada putih, sehingga dapat diketahui pengaruh kadar air terhadap angka kapang dan khamir pada lada putih. Hasil analisis kadar air pada sampel lada putih tercantum pada Gambar 1.

Berdasarkan Gambar 1 terlihat bahwa semua sampel yang di uji memiliki kadar air yang lebih tinggi dari standar mutu 1 SNI (13\%), namun masih berada di bawah standar mutu 2 (18\%). Sampel S2 memiliki kadar air yang paling tinggi dibandingkan dengan sampel lainnya.

Kadar air yang terdapat pada lada putih dipengaruhi oleh kondisi ruang penyimpanan lada putih kering. Kadar air pada sampel dipengaruhi oleh beberapa faktor seperti suhu dan kelembaban lingkungan penyimpanan. Penyimpanan pada lingkungan yang memiliki kelembaban relatif tinggi dapat menyebabkan tingginya kadar air pada lada putih, karena komoditas rempah-rempah bersifat higroskopis (Sembiring dan Hidayat, 2012).

Sampel S5 memiliki kadar air yang paling mendekati standar mutu 1 $(13 \%)$. Penyimpanan pada suhu tinggi $( \pm$ $\left.40^{\circ} \mathrm{C}\right)$ dapat menyebabkan ruang penyimpanan semakin kering sehingga 
kadar air bahan menurun (Sembiring, 2012). Jika kelembaban ruangan lebih rendah daripada kadar air maka sebagian air dalam bahan akan menguap (Wigati, 2009)..

Lama perendaman dan cara pengeringan tidak mempengaruhi kadar air lada putih (Usmiati dan Nurjanah, 2016). Tetapi suhu dan waktu pengeringan lada oleh petani berpengaruh nyata terhadap kadar air (Priyanto et al, 2011).

\section{Hasil Penetapan Angka Kapang dan Khamir (AKK)}

Sampel S1 dan S2 memiliki AKK yang tinggi dan tidak memenuhi syarat mutu BPOM (Gambar 2). Dari semua sampel, sampel S2 memiliki AKK paling tinggi $\left(5,51 \times 10^{4} \mathrm{koloni} / \mathrm{g}\right)$ dan sampel S5 memiliki AKK paling kecil $\left(8,8 \times 10^{2}\right.$ koloni/g). Hal ini menunjukan hubungan antara kadar air pada lada putih dengan AKK. Lada putih yang memiliki kadar air tinggi memiliki AKK yang juga tinggi, sedangkan lada putih yang memiliki kadar air rendah memiki AKK yang rendah.

Kapang menyerang biji-bijian termasuk palawija saat tanaman masih tumbuh di lapangan sampai waktu panen. Kapang biasanya memerlukan kadar air yang relatif tinggi untuk pertumbuhan yaitu 22-25\% (Ahmad, 2009). Beberapa faktor yang menyebabkan kontaminasi kapang dan khamir pada lada putih adalah proses perendaman yang menggunakan air rawa atau air sungai yang kotor, perontokan buah lada dengan cara di injak-injak serta proses penjemuran yang sangat sederhana sehingga memungkinan terjadinya kontaminasi oleh debu, kotoran binatang peliharaan, maupun mikroorganisme (Nurjanah, 2006).

Menurut Usmiati dan Nurjanah (2006) perlakuan yang lebih bersih pada proses perendaman, sebelum pengeringan dan setelah pengeringan lada ternyata tidak berpengaruh terhadap mutu mikrobiologi pada lada putih. Analisis ALT, jamur/kapang dan koliform masih terdeteksi pada lada putih.

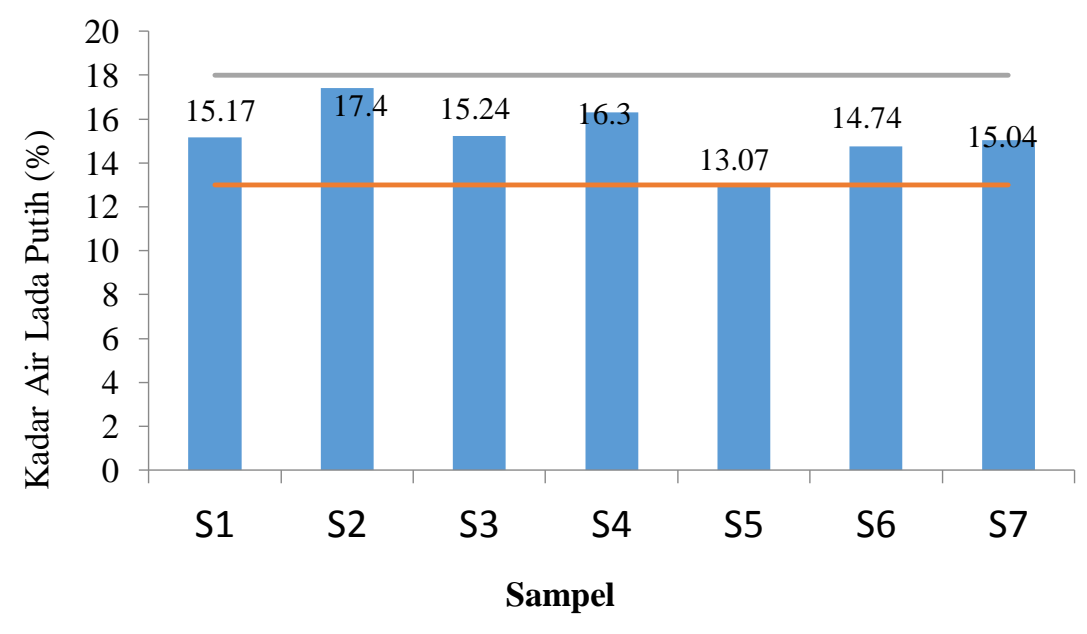

\footnotetext{
Kadar Air Lada Putih pada Sampel ( \% )

— Syarat Mutu 1 Kadar Air Sesuai SNI Lada Putih dan Syarat Mutu 1 Kadar Air Lada Putih Sesuai Aturan PT. Quindofood

- Syarat Mutu 2 Kadar Air Lada Putih Sesuai Aturan PT. Quindofood
}

Gambar 1. Kadar Air Lada Putih 


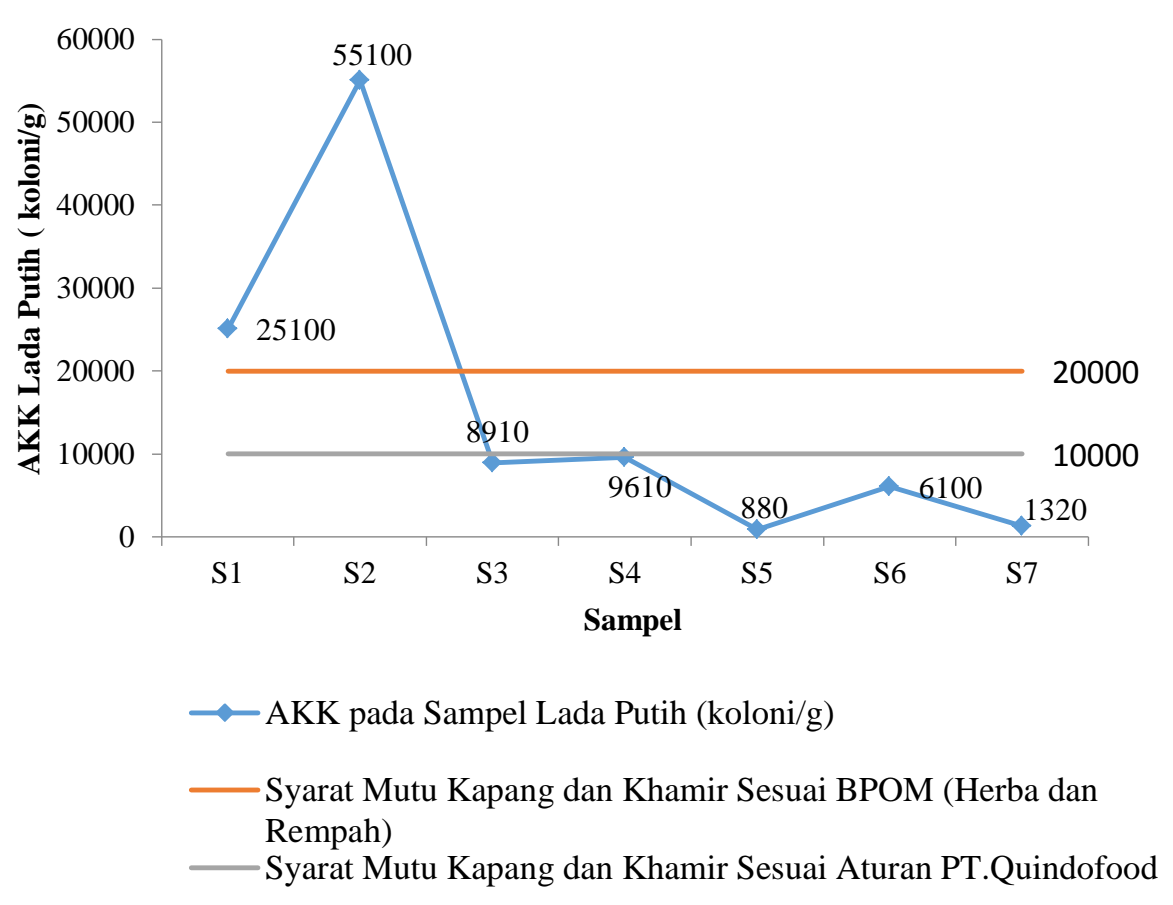

Gambar 2. Angka Kapang dan Khamir

\section{KESIMPULAN}

Semua sampel yang di uji memiliki kadar air yang lebih tinggi dari standar mutu 1 SNI (13\%), namun masih berada di bawah standar mutu 2 (18\%). Sampel S2 memiliki kadar air yang paling tinggi dibandingkan dengan sampel lainnya. Sampel S1 dan S2 memiliki AKK yang tinggi dan tidak memenuhi syarat mutu. BPOM. Dari semua sampel, sampel S2 memiliki AKK paling tinggi $\left(5,51 \times 10^{4}\right.$ koloni/g) dan sampel S5 memiliki AKK paling kecil $\left(8,8 \times 10^{2} \mathrm{koloni} / \mathrm{g}\right)$. Hal ini menunjukan hubungan antara kadar air pada lada putih dengan AKK. Lada putih yang memiliki kadar air tinggi memiliki AKK yang juga tinggi, sedangkan lada putih yang memiliki kadar air rendah memiki AKK yang rendah.

\section{DAFTAR PUSTAKA}

Ahmad, R. Z. 2009. Cemaran Kapang pada Pakan Dan Pengendaliannya. Jurnal Litbang Pertanian 28(1): $15-22$
Badan Pengawas Obat dan Makanan. 2006. Pedoman Cara Pembuatan Obat yang Baik. BPOM RI.

Badan Pengawas Obat dan Makanan. 2009. Penetapan Batas Maksimum Cemaran Mikoba dan Kimia Dalam Makanan.

Nurdjanah, N. 2006. Perbaikan Mutu Lada dalam Rangka Meningkatan Daya Saing di Pasar Dunia. Jurnal. Balai Besar Penelitian dan Pengembangan Pasca Panen Indonesia. Bogor.

Priyanto, G. Yudhia. B. Hamzah 2011. Perubahan Sifat Fisik dan Aktivitas Antioksidan Tepung Rempah. University Jember Press. Jember.

Sembiring, B. dan F, T. Hidayat 2012. Perubahan Mutu Lada Hijau Kering Selama Penyimpanan pada tiga Macam Kemasan dan Tingkatan Suhu. Jurnal Littri: 18 (3) 
Standar Nasional Indonesia.1992.Cara Uji Makanan dan Minuman. 012891-1992. Badan Standarisasi Nasional.

Standar Nasional Indonesia. 2013. Lada Putih. 0004 : 2013. Badan Standarisasi Nasional.

Standar Nasional Indonesia.1992. Cara Uji Cemaran Mikroba 01-2897-1992 2. Badan Standarisasi Nasional .

Usmiati, S. dan N, Nurdjanah. 2006. Pengaruh Lama Perendaman dan Cara Pengeringan Terhadap Mutu Lada Putih. Jurnal. Balai Besar Penelitian dan Pengembangan Pasca Panen Indonesia. Bogor

Wigati, D. 2009.Pengaruh Jenis Kemasan dan Lama Penyimpanan Terhadap Serangan Serangga dan Sifat Fisik Ransum Broiler Starter Berbentuk Crumble. Skripsi. Prodi. Ilmu Nutrisi dan Teknologi Pangan. Isntitut Pertanian Bogor. Bogor.

Yuhono, J.T. 2007. Sistem Agribisinis Lada dan Strategi Pengembangannya. Jurnal Litbang. Balai Penelitian Tanaman Obat dan Aromatik. Bogor 